\title{
Influence of endothelial nitric oxide on neurogenic contraction of human pulmonary arteries
}

\author{
C. Martínez*, E. Cases**, J.M. Vila*, M. Aldasoro*, P. Medina*, V. Marco**, S. Lluch*
}

Influence of endothelial nitric oxide on neurogenic contraction of human pulmonary arteries. C. Martínez, E. Cases, J.M. Vila, M. Aldasoro, P. Medina, V. Marco, S. Lluch. (CERS Journals Ltd 1995.

ABSTRACT: The present study was designed to investigate the contribution of the endothelium and that of the L-arginine pathway on the contractile responses of isolated human pulmonary arteries to electrical field stimulation (EFS) and noradrenaline.

Isometric tension was measured in artery rings obtained from portions of human lung after thoracic surgery for removal of lung carcinoma (18 patients).

Electrical field stimulation (EFS) induced frequency-dependent contractions of isolated human pulmonary arteries which were abolished by tetrodotoxin, guanethidine and prazosin (all at $\mathbf{1 0}^{-6} \mathrm{M}$ ). The increases in tension were of greater magnitude in arteries denuded of endothelium. $\mathrm{N}^{\mathrm{G}}$-nitro-L-arginine methyl ester (L-NAME) $\left(10^{-4} \mathrm{M}\right)$ potentiated the contractile response to EFS in artery rings with endothelium but not in endothelium-denuded arteries. The potentiation induced by L-NAME was completely reversed by $\mathrm{L}$-arginine $\left(10^{-4} \mathrm{M}\right)$ but not by $\mathrm{D}$-arginine $\left(10^{-4} \mathrm{M}\right)$. Indomethacin $\left(3 \times 10^{-6} \mathrm{M}\right)$ had no significant effect on the contractile response to EFS. Contractile responses to noradrenaline were similar in arteries with and without endothelium.

Our results suggest that electrical field stimulation releases endothelium-derived nitric oxide, which inhibits the contractile responses of human pulmonary arteries. Although adrenergic nerves seem to be responsible for the contraction, the transmitter involved in the release of nitric oxide does not appear to be noradrenaline. Eur Respir J., 1995, 8, 1328-1332.

\author{
*Departamento de Fisiología and **De- \\ partamento de Medicina, Universidad de \\ Valencia, 46010 Valencia, Spain. \\ Correspondence: S. Lluch \\ Departamento de Fisiología \\ Universitat de Valencia \\ Blasco Ibañez 17 \\ 46010 Valencia \\ Spain
}

Keywords: Adrenergic stimulation endothelium

human pulmonary artery

nitric oxide

Received: February 131995

Accepted after revision May 201995

This work was supported by the Comisión Interministerial de Ciencia y Tecnología, Ministerio de Sanidad and Generalitat Valenciana.
Nitric oxide (or a substance containing nitric oxide) synthetized from L-arginine plays a decisive role in the responses of vascular smooth muscle to a variety of stimuli [1-3]. Removal of the endothelium produces a significant increase in the contractile response to adrenergic stimulation of arteries from various animal species [4, 5], including man [6]. The inhibitory effect of endothelium on the contractile response to adrenergic nerve stimulation seems to be due to the release of nitric oxide from endothelial cells [6-8]. A direct release of nitric oxide from perivascular nerve endings or from smooth muscle cells has also been considered $[9,10]$.

With regard to human systemic arteries, recent experiments suggest that the presence of intact endothelial cells is a prerequisite for the release of nitric oxide during adrenergic nerve stimulation $[6,11]$. Whether the interaction of nitric oxide with adrenergic nerve-mediated responses can be extrapolated to human pulmonary arteries remains to be determined. Control mechanisms of pulmonary circulation differ in several aspects from those present in the systemic circulation $[12,13]$. Hence, the present study was designed to evaluate the contractile response of isolated human pulmonary arteries to electrical stimulation and exogenous noradrenaline. Obser- vations were made in the presence and absence of endothelium and after exposure to $\mathrm{NG}^{\mathrm{G}}$-nitro-L-arginine methyl ester (L-NAME), an inhibitor of nitric oxide synthase [14].

\section{Methods}

Lung segments were obtained from 18 male patients (mean age $67 \pm 3 \mathrm{yrs}$ ) undergoing thoracic surgery for removal of lung carcinoma. The study was approved by the Ethics Committee of our institution and informed consent was obtained from each patient before the study. After the resection, the samples were placed into physiological salt solution $(\mathrm{NaCl} 0.9 \%)$, kept on ice and transported back to the laboratory. Segmental and subsegmental pulmonary arteries were dissected free and placed in chilled Krebs-Henseleit solution. Arterial rings $(3 \mathrm{~mm}$ in length and 2-3 $\mathrm{mm}$ in outside diameter) were cut for isometric recording of tension. In approximately $50 \%$ of the artery rings the endothelium was removed mechanically by inserting a stainless-steel wire into the lumen and gently rolling the rings on wet filter paper. This procedure removed more than $90 \%$ of the endothelial 
cells, as observed from silver-stained whole-mount sections for light microscopy [15]. Functional integrity of the endothelium was confirmed routinely by the presence of relaxation induced by acetylcholine $\left(10^{-7}\right.$ to $\left.10^{-6} \mathrm{M}\right)$ during contraction obtained with histamine $\left(3 \times 10^{-5} \mathrm{M}\right)$.

Each artery ring was set up in a $4 \mathrm{~mL}$ bath containing modified Krebs-Henseleit solution of the following millimolar (mM) composition: $\mathrm{NaCl} 115$; $\mathrm{KCl} 4.6$; $\mathrm{MgCl}_{2} \cdot 6 \mathrm{H}_{2} \mathrm{O}$ 1.2; $\mathrm{CaCl}_{2} 2.5 ; \mathrm{NaHCO}_{3} 25$; glucose 11.1; and disodium ethylenediamine tetraacetic acid (EDTA) 0.01 . The solution was equilibrated with $95 \% \mathrm{O}_{2}$ and $5 \% \mathrm{CO}_{2}$ to give a $\mathrm{pH}$ of 7.3-7.4. Temperature was maintained at $37^{\circ} \mathrm{C}$. To establish the resting tension for maximal force development, a series of preliminary experiments were performed on artery rings of similar length and outer diameter, which were exposed repeatedly to 60 $\mathrm{mM} \mathrm{KCl}$. Basal tension was increased gradually until contractions were maximal. The optimal resting tension was $2-3 \mathrm{~g}$. The vessels were allowed to attain a steady level of tension during a $2 \mathrm{~h}$ accommodation period before testing.

Electrical field stimulation (EFS) was provided by a Grass S88 stimulator (Grass Instruments, Quincy, USA) via two platinum electrodes positioned on each side and parallel to the axis of the vascular ring. Stimulation parameters used were 4,8 and $16 \mathrm{~Hz}, 15 \mathrm{~V}, 0.25 \mathrm{~ms}$ duration, for $30 \mathrm{~s}$. To assess the nature of the contractile response, the vessel rings were stimulated before and after exposure to tetrodotoxin, guanethidine or prazosin (all at $10^{-6} \mathrm{M}$ ), following the procedure described previously $[6,7]$.

After an initial set of stimulations, the vessel rings were incubated with L-NAME $\left(10^{-4} \mathrm{M}\right)$ for $10 \mathrm{~min}$ and a second set of stimulations was given. The third set of stimulations was given after a 10 min incubation with Larginine or D-arginine $\left(10^{-4} \mathrm{M}\right)$ of rings previously exposed to L-NAME. As a control $(n=6 ; a=9)$, three consecutive sets of stimulation were given at identical intervals. Less than $10 \%$ variability in the magnitude of electrical stimulation-induced contractions was observed for a given ring during three consecutive sets of control stimulations. To assess the possible intervention of endogenous prostaglandins on the neurogenic contraction, electrical stimulation was applied before and $10 \mathrm{~min}$ after the addition of $3 \times 10^{-6} \mathrm{M}$ indomethacin in the organ bath. At the end of each series, tetrodotoxin $\left(10^{-6} \mathrm{M}\right)$ was added and electrical stimulation repeated to confirm the neurogenic nature of the contraction.

Concentration-response curves for noradrenaline were determined from separate artery preparations with and without endothelium. Concentrations of noradrenaline producing half-maximal contractions (EC50) were determined from individual concentration-response curves by nonlinear regression analysis, and from these values the geometric means were calculated [16].

The following drugs were used: acetylcholine chloride, noradrenaline hydrochloride, indomethacin, tetrodotoxin, guanethidine, $\mathrm{NG}^{\mathrm{G}}$-nitro-L-arginine methyl ester, L-arginine hydrochloride, D-arginine hydrochloride, histamine dihydrochloride (Sigma Chemical Co., St. Louis, MO, USA) and prazosin (Pfizer, Kent, UK). Drugs were prepared and diluted in distilled water except for indomethacin, which was dissolved in absolute ethanol and sodium bicarbonate solution $(150 \mathrm{mM})$ and readjusted to $\mathrm{pH}$ 7.4 with $\mathrm{HCl}$ prior to use. Drugs were added to the organ bath in volumes of $<70 \mu \mathrm{L}$. Stock solutions of the drugs were freshly prepared every day.

The contractile response is expressed as a percentage of the maximal tension developed by $60 \mathrm{mM} \mathrm{KCl}$ by each preparation. Results are expressed as means \pm SEM. The results were evaluated statistically by means of paired or unpaired Student's t-test or one-way analysis of variance. A probability value of less than 0.05 was considered to be significant.

\section{Results}

EFS induced frequency-dependent contractions in human pulmonary artery rings which were abolished by $10^{-6} \mathrm{M}$ tetrodotoxin (number of subjects $(\mathrm{n})=8$; number of arterial rings $(\mathrm{a})=20$ ), a neurotoxin, $10^{-6} \mathrm{M}$ guanethidine $(n=2 ; a=5)$, a sympathetic neuron blocker, or $10^{-6}$ $M$ prazosin $(n=2 ; a=6)$, an $\alpha_{1}$-adrenoceptor antagonist (fig. 1). These results indicate that increases in tension were due to the release of noradrenaline from adrenergic nerves acting on $\alpha_{1}$-adrenoceptors.

The contractile responses were of greater magnitude in arteries without endothelium (fig. 2). The increased contraction observed in vessels without endothelium does not reflect a nonspecific effect on smooth muscle, since the contractile response to $\mathrm{KCl}(60 \mathrm{mM})$ was similar in intact $(n=6 ; a=15)$ and denuded $(n=6 ; a=15)$ rings $(1,758 \pm 217$ versus $1,605 \pm 223 \mathrm{mg} ; \mathrm{p}>0.05)$. Arteries

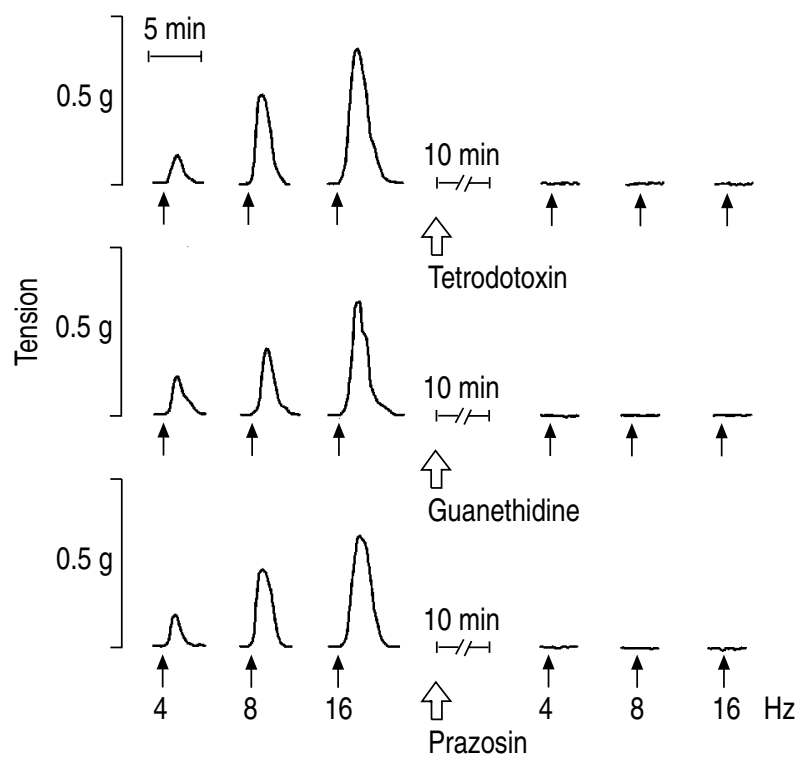

Fig. 1. - Sections of experimental records showing contractile effects of electrical field stimulation on human pulmonary artery in the absence and in the presence of tetrodotoxin $\left(10^{-6} \mathrm{M}\right)$, guanethidine $\left(10^{-6} \mathrm{M}\right)$ or prazosin $\left(10^{-6} \mathrm{M}\right)$. Tracings are representative of various artery rings from different patients. In all cases, the differences of the responses before and after treatment were statistically significant $(\mathrm{p}<0.05)$. 


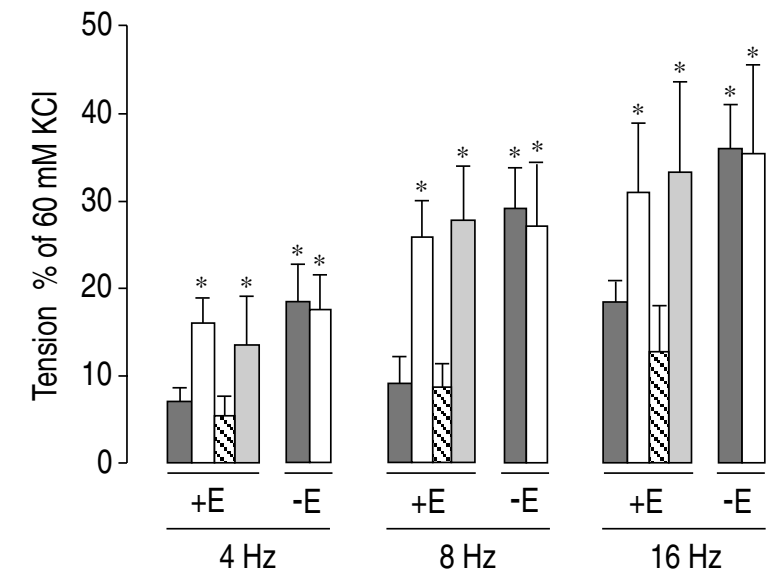

Fig. 2. - Contractile effects of electrical field stimulation in artery rings with $(+E)(n=7 ; a=20)$ and without $(-E)(n=4 ; a=12)$ endothelium. After an initial set of stimulations, rings were stimulated in the presence of $10^{-4} \mathrm{M} \mathrm{L-NAME}$. In arteries with endothelium L-arginine $\left(10^{-4} \mathrm{M}\right)(\mathrm{n}=4 ; \mathrm{a}=12)$ or D-arginine $\left(10^{-4} \mathrm{M}\right)(\mathrm{n}=3 ; \mathrm{a}=8)$ was applied and the stimulation was repeated. *: $\mathrm{p}<0.05$, compared with control rings with endothelium. Results are expressed as percentage of the contraction developed by $60 \mathrm{mM} \mathrm{KCl}$ by each preparation. Values are presented as mean \pm SEM shown by vertical bars. $\square$ : control; $\square$ : L-NAME; $\$$ : L-NAME+L-arginine; $\square$ : L-NAME+D-arginine; LNAME: $\mathrm{N}^{\mathrm{G}}$-nitro-L-arginine methyl ester; $\mathrm{n}$ : number of subjects; a: number of arterial rings.

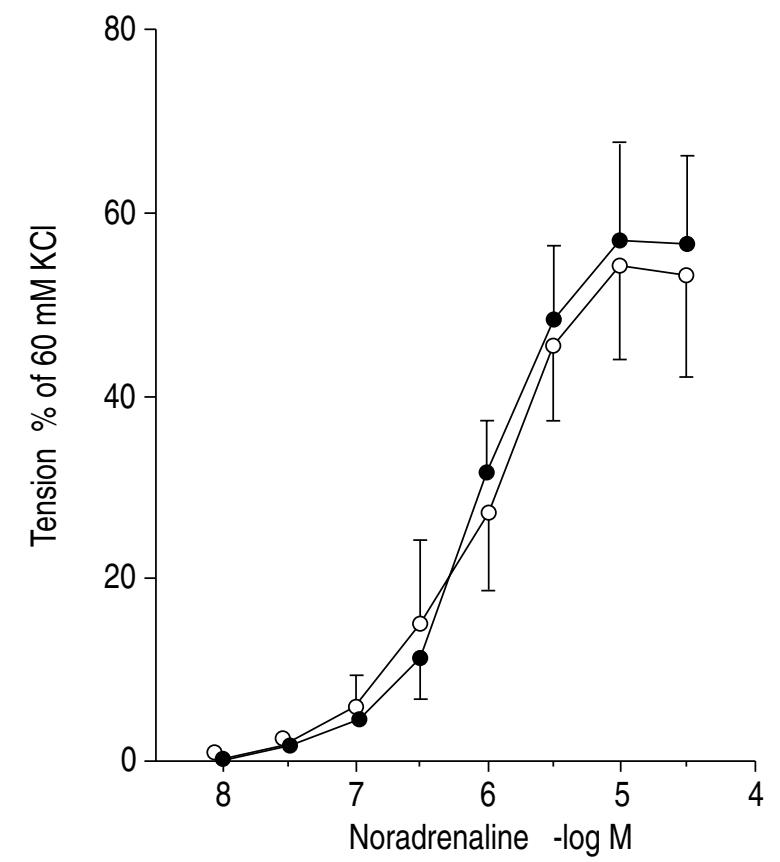

Fig. 3. - Concentration-response curves for noradrenaline determined in artery rings with $(\bullet)(n=4 ; a=14)$ and without $(O)(n=4 ; a=13)$ endothelium. Results are expressed as percentage of the contraction developed by $60 \mathrm{mM} \mathrm{KCl}$ by each preparation. Values are presented as mean \pm SEM shown by vertical bars. n: number of subjects; a: number of arterial rings.

exposed to L-NAME $\left(10^{-6}\right.$ to $\left.10^{-4} \mathrm{M}\right)$ did not show significant changes in resting tension as compared to arteries incubated with Krebs-Henseleit solution (increment in resting tension was $<50 \mathrm{mg} ; \mathrm{p}>0.05$ ). However, LNAME $\left(10^{-4} \mathrm{M}\right)$ significantly enhanced the EFS-induced contractile responses of artery rings with endothelium but did not influence contractile responses of endothelium- denuded arteries (fig. 2). The potentiation induced by L-NAME in arteries with endothelium was completely reversed by L-arginine $\left(10^{-4} \mathrm{M}\right)$, but not by an identical concentration of D-arginine. To test whether prostaglandins are involved in the contractile response to EFS, artery rings were stimulated before and after treatment with the cyclooxygenase inhibitor indomethacin $\left(3 \times 10^{-6}\right.$ $\mathrm{M})$. Contractile responses to EFS of these artery rings were unaffected $(p>0.05)$ after indomethacin treatment (results not shown).

Cumulative application of noradrenaline produced concentration-dependent increases in tension. The EC50 was similar in arteries with $(n=4 ; a=14)$ and without $(n=4$; $\mathrm{a}=13)$ endothelium $\left(1.4 \times 10^{-6}\right.$ vs $1.8 \times 10^{-6} \mathrm{M}$; $\left.\mathrm{p}>0.05\right)$ (fig. 3).

\section{Discussion}

The main findings of the present study can be summarized as follows: 1) removal of endothelium produces a significant increase in the contractile response of human pulmonary arteries to electrical field stimulation; 2) the nitric oxide inhibitor L-NAME augmented neurogenic contractile responses in arteries with endothelium but not in endothelium-denuded arteries; and 3 ) the potentiation induced by L-NAME was reversed by L-arginine (the precursor of nitric oxide production) but not by its inactive isomer $\mathrm{D}$-arginine. These findings suggest that nitric oxide from endothelial cells is responsible for the depressant influence of endothelium on the neurogenic-induced contraction, and agree with previous observations in guinea-pig and rabbit pulmonary arteries [7, 10]. In some vessels [9] as well as in other tissues $[17,18]$, nitric oxide might be directly released from perivascular nerve fibres as a transmitter to counteract neurogenic contractions. However, in the present experiments, L-NAME did not potentiate neurogenic contractions of endothelium denuded arteries, thus suggesting that nitric oxide is derived mainly from endothelial origin. Vasodilator prostaglandins apparently do not modulate the contractile response to electrical field stimulation, since the cyclooxygenase inhibitor indomethacin had no effect on this response.

The augmentation of neurogenic responses by endothelium removal or L-NAME treatment does not appear to be associated with the adrenergic neurotransmitter. The evidence for this is that the endothelium-mediated inhibition was observed in response to electrical field stimulation but not to noradrenaline. As postulated in previous reports $[7,19]$, it is possible that during nerve stimulation other transmitters are released and induce nitric oxide production by endothelial cells, thus leading to partial inhibition of contraction. It could be argued that the thickness of the arterial wall may prevent neurotransmitters from reaching the endothelial cell layer. However, in perfused rabbit ear arteries, it has been reported that a few seconds after perivascular administration of $\left[{ }^{3} \mathrm{H}\right]$ acetylcholine, a considerable amount of the labelled amine was recovered in the vessel lumen, and radioautography revealed an accumulation in the endothelial layer [20]. 
Furthermore, CoHEn and WeIsBrod [21], using rabbit carotid arteries, demonstrated that after stimulation of adrenergic nerve terminals labelled with $\left[{ }^{3} \mathrm{H}\right]$ noradrenaline, $20 \%$ of the released radioactivity overflowed into the luminal side of the vessel.

The effects of noradrenaline on human pulmonary arteries do not appear to be modulated by the release of nitric oxide, since noradrenaline response curves were similar in arteries with and without endothelium. This pattern of endothelium-independent responses has also been shown for vasopressin and endothelin in human cerebral and mesenteric arteries [22-24]. From these results, it can be concluded that under the present experimental conditions the stimulation of adrenoceptors or the increase in smooth muscle tone caused by noradrenaline does not trigger the release of nitric oxide.

It has been reported that a continuous basal release of nitric oxide from vascular endothelium modulates responses in various vascular beds [7, 25]. It appears likely that inhibition of this nitric oxide release by L-NAME would increase basal smooth muscle tone [25, 26]. In the present experiments, L-NAME did not increase resting tension of pulmonary arteries, thus confirming previous reports in human and rat pulmonary arteries [27], and in human mesenteric arteries [6]. Nevertheless, the possibility of basal release of nitric oxide in the absence of contractile effects in response to L-NAME cannot be totally excluded in the present experiments.

In conclusion, the results indicate that endothelial cells of human pulmonary arteries depress the contractile response to electrical field stimulation of intramural nerves by a mechanism involving the release of nitric oxide from these cells. Although adrenergic nerves appear to be responsible for the contractile response, the agent causing the release of nitric oxide does not appear to be noradrenaline. These observations may have clinical implications. In conditions in which disruption of the endothelium or inhibition of nitric oxide synthesis take place, such as in pulmonary hypertension and in chronic lung disease [28, 29], sympathetic tone and, hence, pulmonary vascular resistance may be increased.

\section{References}

1. Ignarro LJ, Byrns RE, Buga GM, Wood KS. Endothelium-derived relaxing factor from pulmonary artery and vein possesses pharmacological and chemical properties that are identical to those of nitric oxide radical. Circ Res 1987; 61: 866-879.

2. Palmer RMJ, Ferrige AG, Moncada S. Nitric oxide release accounts for the biological activity of endotheliumderived relaxing factor. Nature 1987; 327: 524-526.

3. Moncada S, Palmer RMJ, Higgs EA. The discovery of nitric oxide as the endogenous nitrovasodilator. Hypertension 1988; 12: 365-372.

4. Tesfamariam B, Halpern W, Osol G. Effects of perfusion and endothelium on the reactivity of isolated resistance arteries. Blood Vessels 1985; 22: 301-305.

5. Hynes MR, Dang H, Duckles SP. Contractile responses to adrenergic nerve stimulation are enhanced with removal of endothelium in rat caudal artery. Life $\mathrm{Sci}$ 1988; 42: 357-365.
6. Aldasoro M, Martínez C, Vila JM, Flor B, Lluch S. Endothelium-dependent component in the contractile responses of human omental arteries to adrenergic stimulation. Eur J Pharmacol 1993; 250; 103-107.

7. Liu SF, Crawley DE, Evans TW, Barnes PJ. Endogenous nitric oxide modulates adrenergic neural vasoconstriction in guinea-pig pulmonary artery. Br J Pharmacol 1991; 104: 565-569.

8. González C, Estrada C. Nitric oxide mediates neurogenic vasodilation of bovine cerebral arteries. J Cereb Blood Flow Metab 1991; 11: 366-370.

9. Toda N, Okamura T. Mechanism underlying the response to vasodilator nerve stimulation in isolated dog and monkey cerebral arteries. Am J Physiol 1990; 259: H1511-H1517.

10. MacLean MR, McCulloch KM, MacMillan JB, McGrath JC. Influences of the endothelium and hypoxia on neurogenic transmission in the isolated pulmonary artery of the rabbit. Br J Pharmacol 1993; 108: 150154.

11. Martínez C, Vila JM, Aldasoro M, Medina P, Chuan P, Lluch S. The human deferential artery: endotheliummediated contraction in response to adrenergic stimulation. Eur J Pharmacol 1994; 261: 73-78.

12. Hyman AL, Lippton HL, Dempesy CW, et al. Autonomic control of the pulmonary circulation In: Weir EK, Reeves JT, eds. Pulmonary Vascular Physiology and Pathophysiology. New York, Marcel Dekker, 1989; pp. 291-324.

13. Fishman AP. The normal pulmonary circulation. In: Fishman AP, ed. Pulmonary Disease and Disorders. Vol. 1. New York, McGraw-Hill, 1990; pp. 975-997.

14. Rees DD, Palmer RMJ, Hodson HF, Moncada S. A specific inhibitor of nitric oxide formation from L-arginine attenuates endothelium-dependent relaxation. $\mathrm{Br} J$ Pharmacol 1989; 96: 418-424.

15. Caplan BA, Schwartz CJ. Increased endothelial cell turnover in areas of in vivo Evans blue uptake in the pig aorta. Atherosclerosis 1973; 6: 713-719.

16. Fleming WW, Westfall DP, De la Lande IS, Jellet LB. Log-normal distribution of equieffective doses of norepinephrine and acetylcholine in several tissues. $J$ Pharmacol Exp Ther 1972; 181: 339-345.

17. Gillespie JS, Liu XR, Martin W. The effects of L-arginine and $\mathrm{NG}^{\mathrm{G}}$-mono-methyl L-arginine on the response of the rat anococcygeus muscle to NANC nerve stimulation. Br J Pharmacol 1989; 98: 1080-1082.

18. Tucker JF, Brave SR, Charalambous L, Hobbs AJ, Gibson A. L-NG-nitro arginine inhibits nonadrenergic, noncholinergic relaxations of guinea-pig isolated tracheal smooth muscle. Br J Pharmacol 1990; 100: 663664.

19. Shinozuka K, Kobayashi Y, Shimoura K, Hattori K. Role of nitric oxide from the endothelium on the neurogenic contractile responses of rabbit pulmonary artery. Eur $J$ Pharmacol 1992; 222: 113-120.

20. González M, Martin C, Hamel E, Galea E, Gómez B, Lluch S. Endothelial cells inhibit the vascular response to adrenergic nerve stimulation by a receptor-mediated mechanism. Can J Physiol Pharmacol 1990; 68: 104109.

21. Cohen R, Weisbrod R. Endothelium inhibits norepinephrine release from adrenergic nerves of rabbit carotid artery. Am J Physiol 1988; 254: H871-H878.

22. Martín de Aguilera E, Vila JM, et al. Endotheliumindependent contractions of human cerebral arteries in response to vasopressin. Stroke 1990; 21: 1689-1693. 
23. Martín de Aguilera E, Irurzun A, et al. Role of endothelium and calcium channels in endothelin-induced contraction of human cerebral arteries. Br J Pharmacol 1990; 99: 439.

24. Vila JM, Martín de Aguilera E, Irurzun A, Aldasoro M, Flor B, Lluch S. Contractile response of human omental arteries to endothelin. J Pharm Pharmacol 1992; 44: 105-108.

25. Rees DD, Palmer RMJ, Moncada S. Role of endothelium-derived nitric oxide in the regulation of blood pressure. Proc Natl Acad Sci USA 1989; 86: 33753378.

26. Moncada S, Palmer RMJ, Higgs EA. Nitric oxide: phys- iology, pathophysiology and pharmacology. Pharmacol Rev 1991; 43: 109-142.

27. Crawley DE, Liu SF, Evans TW, Barnes PJ. Inhibitory role of endothelium-derived relaxing factor in rat and human pulmonary arteries. Br J Pharmacol 1990; 101: 166-170.

28. Dinh-Xuan AT, Higenbottam TW, Clelland CA, et al. Impairment of endothelium-dependent pulmonary-artery relaxation in chronic obstructive lung disease. $N$ Engl $J$ Med 1991; 324: 1539-1547.

29. Rosenberg HC, Rabinovitch M. Endothelial injury and vascular reactivity in monocrotaline pulmonary hypertension. Am J Physiol 1986; 255: H1484-H1491. 